\title{
Preclinical Labor-and-Delivery Shadowing: The Impact on Medical Students' Perceptions of Obstetrics and Gynecology
}

\author{
Sarah Dotters-Katz, MD, MMHPE ${ }^{1}$ Alexis Panzer, BA ${ }^{2}$ Matthew Givens, MD ${ }^{3}$ \\ Marcela Smid, MD, MA, MS ${ }^{4}$ Alice Chuang, MD, Med ${ }^{5}$ \\ ${ }^{1}$ Department of Obstetrics and Gynecology, Duke University, \\ Durham, North Carolina \\ 2 University of North Carolina Medical School, Chapel Hill, North Carolina \\ ${ }^{3}$ Department of Obstetrics and Gynecology, University of North \\ Carolina, Chapel Hill, North Carolina \\ ${ }^{4}$ Department of Obstetrics and Gynecology, University of Utah, Salt \\ Lake City, Utah \\ ${ }^{5}$ Department of Obstetrics and Gynecology, University of North \\ Carolina, Chapel Hill, North Carolina \\ Address for correspondence Sarah Dotters-Katz, MD, Duke Maternal \\ Fetal Medicine, Duke Perinatal Consultants of Durham and Fetal \\ Diagnostic Center, 2608 Erwin Road, STE 210, Durham, NC 27705 \\ (e-mail: sd132@duke.edu). \\ Am J Perinatol Rep 2018;8:e64-e67.
}

\begin{abstract}
Objective We sought to determine the impact of preclinical exposure (shadowing) to labor and delivery (L\&D) on medical students' perceptions of obstetrics and gynecology (OB/GYN).

Study Design We administered a written survey to rising third-year medical students at a single center prior to any clerkship. We described motivation/deterrents for shadowing among students, and experiences/perceptions of those students who shadowed.

Results In total, 119/136 (86\%) students completed the survey. Of those, 29\% participated in shadowing on L\&D. Participating students were more likely to be female (79 vs. $21 \% ; p<0.01)$ and in their first year $(85 \%)$. Ninety-one percent participated because they wanted more exposure to $\mathrm{OB} / \mathrm{GYN}$, whereas only $53 \%$ they were interested in $\mathrm{OB} / \mathrm{GYN}$. Students who did not shadow indicated not having enough time as the main reason. After participation, $82 \%$ had more perspective on $\mathrm{OB} / \mathrm{GYN}$ than prior to shadowing. Ninety-seven percent felt that the experience was worthwhile; $62 \%$ stated based on their experience that

Keywords

- labor and delivery

- preclinical exposure

- shadow

- obstetrics they were likely to consider a career in $\mathrm{OB} / \mathrm{GYN}$. All students who participated stated that they would opt to shadow again if given the opportunity.

Conclusion Students who have L\&D shadowing exposure report very positive experiences and express desire for increased opportunities. OB/GYN departments may consider increasing availability of L\&D shadowing opportunities for preclinical medical students.
\end{abstract}

Shadowing, or observing medical providers and procedures, is an experience that is common in medical education. Shadowing medical providers has been demonstrated to increase exposure to a field of practice and enhance learning for a wide spectrum of learners. ${ }^{1-3}$

For medical students in the preclinical years, shadowing offers exposure to the inpatient services and patient care prior

received

September 6, 2017

accepted after revision

February 23, 2018
DOI https://doi.org/

$10.1055 / \mathrm{s}-0038-1641723$

ISSN 2157-6998. to initiation of formal clerkships. Data from shadowing in surgical subspecialties suggest that early exposure may increase interest in surgical fields and ultimately lead more students to choose surgery as a career. ${ }^{4,5}$ However, not all shadowing leads to increased interest. Some data on shadowing in the emergency department suggests that early exposure may actually decrease students' interest in that specialty. ${ }^{6}$
Copyright $\odot 2018$ by Thieme Medical Publishers, Inc., 333 Seventh Avenue, New York, NY 10001, USA. Tel: +1(212) 584-4662.
License terms

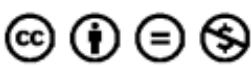


Although preclinical shadowing opportunities in labor and delivery units (L\&D) are common, no data exist regarding the impact of participation on students' perceptions of obstetrics and gynecology (OB/GYN). Our objective was to assess the impact of preclinical shadowing exposure to $\mathrm{OB} /$ GYN on students' perceptions and career interest.

\section{Materials and Methods}

We conducted a survey of rising third-year medical students from the University of North Carolina (UNC) who had completed their preclinical years. The study was reviewed by the UNC Chapel Hill Office of Human Research Ethics and determined to be exempt from further review.

A panel of subject matter experts designed a survey to assess medical student experiences and perceptions relating to their time spent shadowing on L\&D. The survey was edited by a focus group of graduate medical trainees and then piloted by a small group of preclinical medical students for clarity and brevity. Based on their feedback, the survey was edited. The final survey included 2 demographic questions, 6 closed-ended questions for those did not shadow, and 14 closed-ended questions for those who did shadow. Students who did shadow answered questions regarding their time on L\&D, such as what they saw and who they spent time with, as well as questions about how the experience affected their perceptions of OB/GYN. Both groups were asked about the rationale behind their choice to shadow (or not to shadow) as well as if they would shadow again if given the opportunity.

A paper survey was given to students during a large group session of their "transitions" course, a class designed to prepare them for clinical years. Students were given the paper survey upon entry to the classroom and were asked to hand them to the center aisle prior to the start of the session. Since this session was required for all students to attend, we assumed that the total number of students who were present was equal to the number of students who complete the clinical years at UNC. The surveys were anonymous, and there was no way to connect the survey back to any individual student after it was completed.

The survey results were entered into Qualtrics software (Qualtrics, Provo, UT). Demographics of students who participated in shadowing were compared with demographics of those who did not. Among students who did not shadow, the rationale for not shadowing was compared based on gender and age. Older students were defined as those over 25 years of age. The data were analyzed using descriptive statistics. Analyses were performed using STATA (version 13, StataCorp, College Station, TX). Common themes were analyzed from free-text responses.

\section{Results}

Of the 136 rising third-year medical students, 119 were assigned to Chapel Hill as their clerkship site completed the survey (response rate: $86 \%$ ). Of respondents, 29\% (34) students shadowed on L\&D at least once during their preclinical years. Students who shadowed were more likely to be female (79 vs. $37 \%$; $p<0.01$ ). There were no differences in age or prior L\&D exposure between students who did and those who did not shadow (- Table $\mathbf{1}$ ).

Among students who did not participate in shadowing, $28 \%$ cited lack of time and $27 \%$ cited lack of interest in $\mathrm{OB} /$ GYN as the reasons for not electing to shadow (-Table 2 ). Among students who did shadow, the most important reason for shadowing was a desire for more exposure to OB/GYN (44\%). Many students also elected to shadow because it "seemed fun" (Table 3). There were no differences in the rationale for shadowing based on gender or age. The vast majority of students shadowed in the first year of medical school (85\%) and only shadowed once (88\%).

Of students who did shadow, $85 \%$ saw a delivery. Of those, $79 \%$ saw a vaginal delivery, $27 \%$ saw a cesarean section, and $21 \%$ saw both (Table 4 ). Forty-four percent participated in clinical rounds with the team, and $41 \%$ participated in the evaluation of a patient in triage. Most students described

Table 1 Student demographics

\begin{tabular}{|c|c|c|c|}
\hline & $\begin{array}{l}\text { Shadow, } \\
n=34(\%)\end{array}$ & $\begin{array}{l}\text { No shadow, } \\
n=85(\%)\end{array}$ & $p$-Value \\
\hline \multicolumn{4}{|l|}{ Gender } \\
\hline Male & 7 (20.6) & $54(63.5)$ & \multirow[t]{2}{*}{$<0.01$} \\
\hline Female & $27(79.4)$ & 31 (36.5) & \\
\hline \multicolumn{4}{|l|}{ Age (years) } \\
\hline $20-25$ & $20(58.8)$ & $43(50.6)$ & \multirow[t]{4}{*}{0.5} \\
\hline $26-30$ & $13(38.3)$ & $40(47.1)$ & \\
\hline $31-35$ & 0 & $1(1.2)$ & \\
\hline$>35$ & $1(2.9)$ & $1(1.2)$ & \\
\hline $\begin{array}{l}\text { Previous exposure } \\
\text { to delivery }\end{array}$ & $7(20.6)$ & $17(20)$ & 1 \\
\hline $\begin{array}{l}\text { Prior L\&D } \\
\text { shadowing } \\
\text { experience }\end{array}$ & $4(11.8)$ & $8(9.4)$ & 0.7 \\
\hline $\begin{array}{l}\text { Would do it again } \\
\text { if had a chance }\end{array}$ & $34(100)$ & 39 (45.9) & $<0.01$ \\
\hline
\end{tabular}

Abbreviation: L\&D, labor and delivery.

Table 2 Rationale for not shadowing $(n=85)$

\begin{tabular}{|l|l|}
\hline $\begin{array}{l}\text { Most important reason for } \\
\text { not shadowing }\end{array}$ & $\begin{array}{l}\text { Total students who } \\
\text { selected this option, } \boldsymbol{n} \text { (\%) }\end{array}$ \\
\hline Did not have time & $24(28)$ \\
\hline Not interested in OB/GYN ${ }^{\mathrm{a}}$ & $23(27)$ \\
\hline Enough exposure later & $16(19)$ \\
\hline No free slots & $14(17)$ \\
\hline Other & $8(9)$ \\
\hline Prior shadowing experience & $0(0)$ \\
\hline
\end{tabular}

Abbreviation: $\mathrm{OB} / \mathrm{GYN}$, obstetrics and gynecology.

a Older students were more likely to not shadow because they were not interested (38.1 vs. $16.3 \%$; $p=0.024$ ). 
Table 3 Rationale for shadowing $(n=34)$

\begin{tabular}{|l|l|}
\hline $\begin{array}{l}\text { Most important reason for } \\
\text { shadowing }^{\text {a }}\end{array}$ & $\begin{array}{l}\text { Total students who se- } \\
\text { lected this option, } \boldsymbol{n}(\%)\end{array}$ \\
\hline Interested in OB/GYN & $9(27)$ \\
\hline Wanted more exposure & $15(44)$ \\
\hline Seemed fun & $10(29)$ \\
\hline Other & 0 \\
\hline
\end{tabular}

Abbreviation: $\mathrm{OB} / \mathrm{GYN}$, obstetrics and gynecology.

${ }^{a}$ No significant differences by age or gender.

spending the majority of their time with the intern, though $29 \%$ spent the majority of their time with an upper level resident and $24 \%$ with the attending students.

Students who did shadow overwhelmingly described the experience as worthwhile (97.1\%), with no students feeling that it was not a valuable opportunity. Eighty-two percent of students, $71 \%$ (5/7) males and 48\% (14/27) females, who shadowed thought about $\mathrm{OB} / \mathrm{GYN}$ in a more positive way as a result of their time on L\&D. As a result of shadowing, $62 \%$ of students stated they were more likely to consider $\mathrm{OB} / \mathrm{GYN}$ as a career, including $32 \%$ who felt they were much more likely to consider it. Students felt that the providers they worked with altered their opinions on $\mathrm{OB} / \mathrm{GYN}$ in a positive way $85 \%$ of the time. Every male who shadowed described feeling this way. Providers impacted opinions on $\mathrm{OB} / \mathrm{GYN}$ in a very positive way for $41 \%$ of students. Observing procedures was also impactful, with nearly $75 \%$ (25/34) of students noting that procedures changed their perceptions of $\mathrm{OB} /$ GYN in a positive way; this included almost 30\% (10/34) who felt that procedures changed their opinions in a very positive way. The only student who described procedures impacting

Table 4 Shadowing experience $(n=34)$

\begin{tabular}{|l|l|}
\hline & $\begin{array}{l}\text { Total number of } \\
\text { students, } \boldsymbol{n}(\%)\end{array}$ \\
\hline Experiences $^{\text {a }}$ & $29(85)$ \\
\hline Saw any delivery & $27(79)$ \\
\hline Saw vaginal delivery & $9(27)$ \\
\hline Saw cesarean section & $15(44)$ \\
\hline Saw rounds & $14(41)$ \\
\hline Saw patient in triage & $3(9)$ \\
\hline Saw other & $16(47)$ \\
\hline Majority of time spent with & b \\
\hline Intern & $10(29)$ \\
\hline Resident & $8(24)$ \\
\hline Attending students &
\end{tabular}

${ }^{a}$ No significant differences based on gender or age.

bolder students were less likely to spend time with the attending students compared with younger students ( 19 vs. $61 \% ; p=0.02$ ). There were no significant differences based on gender. perceptions in a very negative way witnessed a shoulder dystocia.

In the free-text comments $(n=12)$, students who did not shadow commonly requested more availability and opportunities to shadow (3/5), saying things such as "Really wish I could have shadowed." and "More availability would be much appreciated." Among those who did shadow, 71\% (5/ 7) commented that the experience itself was impactful to them. One student said, "I saw a twin vaginal breech and it changed everything," whereas another commented, "This was a valuable experience that helped to inform my career interests." Another student said, "I would recommend it to anyone wanting more $\mathrm{OB} / \mathrm{GYN}$ exposure or just interested in general."

\section{Discussion}

This study demonstrated that preclinical exposure to L\&D can have a positive impact on medical students' perceptions of $\mathrm{OB} / \mathrm{GYN}$ as a specialty. We also found that the shadowing opportunity increased students' interest in $\mathrm{OB} / \mathrm{GYN}$ as a career. Students almost unanimously found the experience worthwhile. Students overwhelmingly stated wanting more exposure to $\mathrm{OB} / \mathrm{GYN}$ as a rationale for shadowing, and only approximately half of students who shadowed did so because of an interest in $\mathrm{OB} / \mathrm{GYN}$. Finally, nearly half of those who did not shadow, would have if liked to if they were given the opportunity again.

This study looks specifically at the impact of preclinical exposure on medical students' perceptions of $\mathrm{OB} / \mathrm{GYN}$, which is poorly described previously in the literature. Most data regarding $\mathrm{OB} / \mathrm{GYN}$ as a career choice come from students after their clerkships. Chang et al surveyed 81 students at the completion of their $\mathrm{OB} / \mathrm{GYN}$ clerkship to identify factors associated with interest in $\mathrm{OB} / \mathrm{GYN} .{ }^{7}$ Having positive resident role models and feeling like part of the team were the factors most correlated with students' interest in $\mathrm{OB} /$ GYN. In our study, more than $75 \%$ of students spent the majority of their time with residents and almost half rounded with the team. Similarly, Blanchard et al surveyed 153 students matching in $\mathrm{OB} / \mathrm{GYN}$ to determine which factors impacted their career choice. ${ }^{8}$ Among this group, third-year clerkship, fourth-year electives, and an OB/GYN mentor were all of high importance. Again, this study did not include any mention of preclinical exposures. Fogarty et al surveyed 10 years' worth of graduates from a single medical school to understand factors impacting career choice. ${ }^{9}$ This study found that exposure to an OB/GYN faculty in a small group learning environment in the second year was significantly associated with $\mathrm{OB} / \mathrm{GYN}$ as a career choice. The authors hypothesized this finding to be because of a curricular change in the second year to a system-based small group oriented curriculum during the study period. This finding suggests that any exposure, clinical or nonclinical, can be impactful in career choice.

Our study's primary strength is that it addresses a very commonly offered experience (L\&D shadowing), but minimal data exist regarding its impact on students. Our survey was 
designed by subject-matter experts, edited by graduate medical trainees, and piloted prior to implementation to avoid unclear or ineffective questions. Additionally, by using a paper survey at a required course session, we were able to obtain a very high response rate. Finally, the survey was anonymous and administered prior to starting any clerkships, minimizing student concern regarding effects on grades or desire to inflate responses. However, there are weaknesses as well. Our study's primary weakness is that the survey was administered up to 2 years after the shadowing experiences, increasing the risk of recall bias. While our sample size was small, to our knowledge, it represents the largest study to date of students who have shadowed on L\&D during their preclinical years. We must also note that UNC has three sites for the clinical years, and we only surveyed the students who were completing their clinical years at UNC. This does represent more than $75 \%$ of all rising third-year students. Finally, no validated tool regarding shadowing experiences exists; thus, we needed to develop and use a nonvalidated instrument.

Despite these limitations, this study highlights three elements related to L\&D shadowing programs. First, shadowing appears to increase interest in $\mathrm{OB} / \mathrm{GYN}$ as a career. Second, students almost universally felt the experience was worthwhile. Finally, many students elected to shadow not because of an interest in a career in our field but because they desired more exposure. In the future, prospective data in the form of a survey before shadowing, after shadowing, and 3 to 6 months after shadowing might help to assess the impact of shadowing on perceptions of $\mathrm{OB} / \mathrm{GYN}$ and career choice on an individual level directly. These data suggest that shadowing on L\&D impacts students' perceptions on $\mathrm{OB} / \mathrm{GYN}$ in a positive way and could be a motivation for $\mathrm{OB} / \mathrm{GYN}$ departments to continue to invest in these sorts of preclinical experiences.

\section{Ethical Approval}

Ethical approval was granted by the Institutional Review Board at the University of North Carolina on January 8, 2016 (IRB\#15-3100-Exempt).

\section{Conflict of Interest}

The authors report no conflict of interest.
Funding

None.

\section{Presentation}

This study was presented, in part, as a poster presentation at the American College of Obstetricians and Gynecologists Council on Resident Education in Obstetrics and Gynecology National Meeting in Orlando, FL, in March, 2017.

Acknowledgments

We acknowledge Sara Tinkham, the former clerkship coordinator at our institution, who helped schedule shadowing experiences.

\section{References}

1 Soo J, Brett-MacLean P, Cave MT, Oswald A. At the precipice: a prospective exploration of medical students' expectations of the pre-clerkship to clerkship transition. Adv Health Sci Educ Theory Pract 2016;21(01):141-162

2 Turner SR, White J, Poth C, Rogers WT. Preparing students for clerkship: a resident shadowing program. Acad Med 2012;87(09): 1288-1291

3 Wang JY, Lin H, Lewis PY, Fetterman DM, Gesundheit N. Is a career in medicine the right choice? The impact of a physician shadowing program on undergraduate premedical students. Acad Med 2015;90(05):629-633

4 Allen JG, Weiss ES, Patel ND, et al. Inspiring medical students to pursue surgical careers: outcomes from our cardiothoracic surgery research program. Ann Thorac Surg 2009;87(06):1816-1819

5 Drolet BC, Sangisetty S, Mulvaney PM, Ryder BA, Cioffi WG. A mentorship-based preclinical elective increases exposure, confidence, and interest in surgery. Am J Surg 2014;207(02):179-186

6 Gharahbaghian L, Hindiyeh R, Langdorf MI, et al. The effect of emergency department observational experience on medical student interest in emergency medicine. J Emerg Med 2011;40 (04):458-462

7 Chang JC, Odrobina MR, McIntyre-Seltman K. Residents as role models: the effect of the obstetrics and gynecology clerkship on medical students' career interest. J Grad Med Educ 2010;2(03): 341-345

8 Blanchard MH, Autry AM, Brown HL, et al. A multicenter study to determine motivating factors for residents pursuing obstetrics and gynecology. Am J Obstet Gynecol 2005;193(05):1835-1841

9 Fogarty CA, Bonebrake RG, Fleming AD, Haynatzki G. Obstetrics and gynecology-to be or not to be? Factors influencing one's decision. Am J Obstet Gynecol 2003;189(03):652-654 